\title{
GESTÃO DAS ÁGUAS NA REGIÃO METROPOLITANA DE SOROCABA IMPACTOS PARA A AGRICULTURA E MEIO AMBIENTE
}

\author{
Francisco Carlos Ribeiro ${ }^{1}$ \\ André Cordeiro Alves dos Santos ${ }^{2}$ \\ Eleusa Maria da Silva ${ }^{3}$ \\ Alessandra Albuquerque Simoa ${ }^{4}$
}

\section{RESUMO}

O recorte territorial da Região Metropolitana de Sorocaba é diferente do recorte de uma Bacia e de seus Comitês. Quando se pensa planejamento hídrico, é de fundamental importância entender a complexidade e criar mecanismos de diálogos e pactuação que viabilizarão ações em recortes espaciais tão distintos, pois, existem municípios na Região Metropolitana de Sorocaba que pertencem à outras bacias do que o Sorocaba e Médio Tietê, por outro lado, existem munícios que pertencem à nossa Bacia Hidrográfica, mas que não fazer parte da Região Metropolitana. A Região Metropolitana está iniciando a construção do seu Plano Diretor Urbano Integrado (PDUI) que disciplinará a ação antrópica. Compatibilizar planejamento territorial com criação mecanismos de pactuação com os Comitês de Bacias é uma tarefa necessária.

Palavras-chave: Planejamento hídrico; Gestão; Planejamento territorial; Políticas públicas; Meio ambiente.

1 Faculdade de Tecnologia José Crespo Gonzales - Fatec Sorocaba. francisco.ribeiro@fatec. sp.gov.br.

2 Universidade Federal de São Carlos UFSCar - Campus Sorocaba.

3 Comissão de Meio Ambiente - OAB - Votorantim.

4 Universidade Federal de São Carlos (UFSCar) - Campus Sorocaba. 


\section{INTRODUÇÃO}

A Região Metropolitana de Sorocaba foi criada em 2014, contendo 27 municípios. Sua população é de 2.066.986 habitantes. Já o Comitê de Bacia congrega 35 municípios com sede na UGRHI 10 (Unidade de Gerenciamento de Recursos Hídricos) definido pela Lei Estadual n. 7.633 de 1990 esta unidade também é conhecida como Bacia do Rio Sorocaba e Médio Tietê. Ambos recortes geográficos são definidos para gestão e planejamento.

Ocorre que os recortes territoriais são distintos. Os municípios que compõe o $\mathrm{CBH}$ são agrupados pela posição na bacia hidrográfica. Os que compõem uma Região Metropolitana, os oriundos da conurbação da integração e outros fatores históricos e políticos. Tais recortes não coincidem em sua totalidade, e, como veremos, existem municípios que estão na Bacia Hidrográfica do Sorocaba e Médio Tietê e que não estão na Região Metropolitana de Sorocaba e vice-versa. O alinhamento de ações e de planejamento, em situações distintas de interesse, portanto de foros de discussão e pressão política, apresenta-se como um desafio a ser superado.

Por outro lado, a diferença da práxis política entre cidades pequenas e metropolitanas se apresenta como mais um desafio. $\mathrm{O}$ objetivo desse artigo será evidenciar tais alguns destes desafios.

\section{A REGIÃO METROPOLITANA DE SOROCABA E SEUS RECURSOS HÍDRICOS}

A Região Metropolitana de Sorocaba foi criada pela Lei Complementar 1.241 de 08 de maio de 2014. Compunham a Região, 26 municípios, Alambari, Alumínio, Araçariguama, Araçoiaba da Serra, Boituva, Capela do Alto, Cerquilho, Cesário Lange, Ibiúna, Iperó, Itu, Jumirim, Mairinque, Piedade, Pilar do Sul, Porto Feliz, Salto, Salto de Pirapora, São Miguel Arcanjo, São Roque, Sarapuí, Sorocaba, Tapiraí, Tatuí, Tietê e Votorantim. O município de Itapetininga foi integrado à Região Metropolitana, através da Lei Complementar 1.289 de 29 de junho de 2016, sendo então, essa região metropolitana, composta de 27 municípios.

A Região Metropolitana de Sorocaba possui três sub-regiōes (Figura 1), conforme dispôs o artigo $4^{\circ}$ da Lei Complementar 1.41/2014. O mesmo artigo estabeleceu em seu parágrafo único que:

Caberá ao Conselho de Desenvolvimento da Região Metropolitana de Sorocaba, instituído pelo artigo $5^{\circ}$ desta lei complementar, estabelecer em regimento próprio as normas relativas ao processo de organização e funcionamento das sub-regiões a que se refere este artigo. 
Figura 1 Região Metropolitana de Sorocaba e suas sub-regiões.

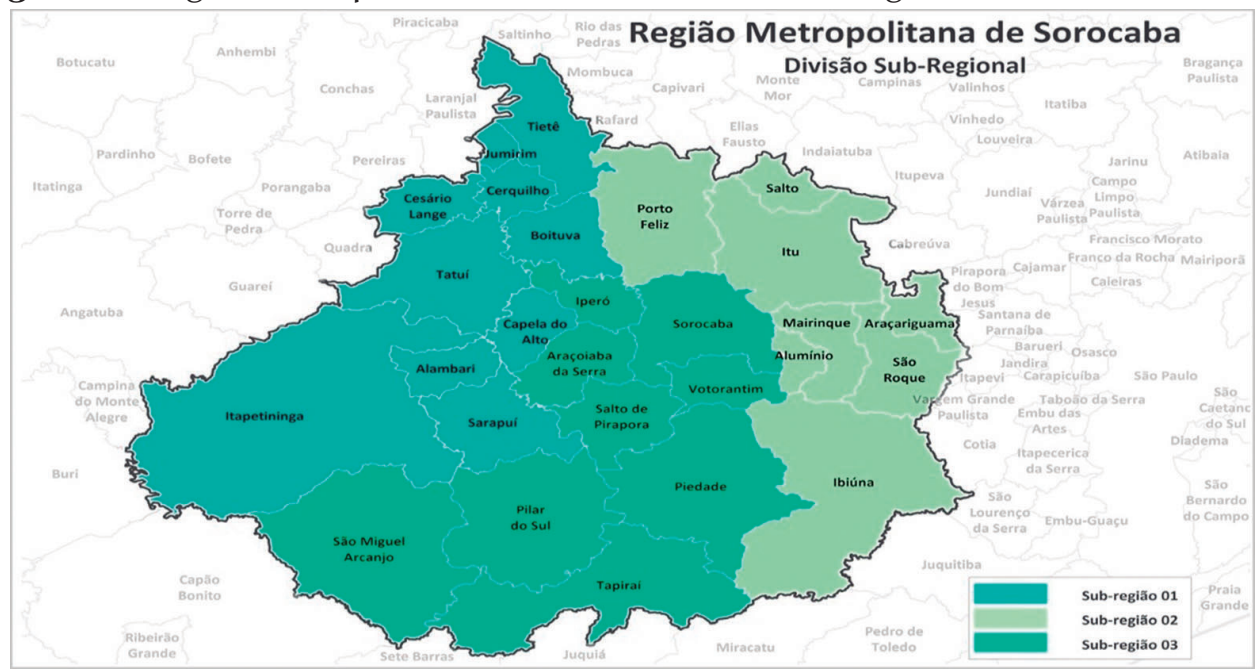

Fonte: Emplasa. Disponível em: https://www.emplasa.sp.gov.br/RMS.

Tabela 1 Região Metropolitana e Comparativo com o Estado.

\begin{tabular}{|l|c|c|c|}
\hline Variável de comparação & RM Sorocaba & Estado de São Paulo & Participação \\
\hline Área $\mathrm{km}^{2}$ & $11.612,33$ & $248.222,36$ & $4,68 \%$ \\
\hline População & 2.066 .986 & 43.359 .005 & $4,77 \%$ \\
\hline PIB & 78.908 .590 & $1.858 .196 .055,52$ & $4,25 \%$ \\
\hline
\end{tabular}

Fonte: Elaboração dos autores, adaptado da Emplasa, Disponível em: https://www.emplasa.sp. gov.br/RMS ajustado com os dados Seade.

Com uma população de mais de dois milhões de habitantes a região metropolitana de Sorocaba tem mais de 4\% do PIB do Estado (Tabela 1) e uma grande atividade agrícola (Tabela 2 ).

Tabela 2 Regiões Metropolitanas por ordem de participação do Setor Agropecuário no valor adicionado.

\begin{tabular}{|l|c|}
\hline \multicolumn{1}{|c|}{ Regiões metropolitanas } & Participação da Agropecuária (\%) \\
\hline Região Metropolitana de Ribeirão Preto & 4,52 \\
\hline Região Metropolitana de Sorocaba & 2,66 \\
\hline Região Metropolitana de Campinas & 1,13 \\
\hline Região Metropolitana do Vale do Paraíba e Litoral Norte & 0,51 \\
\hline Região Metropolitana da Baixada Santista & 0,23 \\
\hline Região Metropolitana de São Paulo & 0,17 \\
\hline
\end{tabular}

Fonte: Elaboração dos autores, com dados do Seade. 
Conforme Pesquisa inédita produzida por Ribeiro et al. (2017) a Região Metropolitana de Sorocaba, produz, entre 1.137.884,46 a 1.141.796,68 toneladas anuais de produtos Olerícolas, representando respectivamente 19,96 a 20,02\% da Produção total do estado de São Paulo, com valor bruto da Produção entre 1.755.686.900,00 a $\mathrm{R} \$ 1.915 .170 .620,00$, representando respectivamente 22,15 a $24,16 \%$ de toda a produção do Estado.

Assim, a gestão dos recursos hídricos, na segunda Região Metropolitana com maior valor adicionado da Agropecuária, ganha uma importância adicional.

\subsection{Bacias Hidrográficas e Região Metropolitana de Sorocaba}

\subsubsection{Bacia Hidrográfica}

Dicionário Livre de Geociências (2011 apud Cibim, 2012, p. 25) traz uma definição didática de bacia hidrográfica ou bacia de drenagem:

Área drenada por um rio e seus afluentes. A delimitação de uma bacia hidrográfica se faz através dos divisores de água que captam as águas pluviais e as desviam para um dos cursos d'água desta bacia. A bacia hidrográfica pode ter diversas ordens e dentro de uma bacia podem ser delimitadas bacias menores. A nomenclatura de uma bacia hidrográfica é dada pelo principal rio ou curso de água por onde ocorre a descarga da água drenada por esta bacia, desconsiderando o fluxo de água subterrâneo, que pode, até certo ponto, ser independente da bacia, ou bacias, sob a qual ocorre. Em princípio, a quantidade de água que se precipita numa bacia hidrográfica deve ser igual à quantidade de água que é descarregada pelo seu principal curso de água, subtraindo-se a água que evapora. Se houver sistemas subterrâneos confinados, é necessário levar em consideração a dinâmica de seu fluxo.

A bacia hidrográfica como unidade geográfica é ideal para se caracterizar, diagnosticar, avaliar e planejar o uso dos recursos (HOLLANDA, 2012). Porém, o recorte geográfico de uma bacia hidrográfica não coincide com os limites dos municípios, nem tão pouco com uma região metropolitana, a qual possui suas próprias regras.

O uso da bacia hidrográfica como base territorial para a gestão dos recursos hídricos não é recente, nos levando a séculos da história desde a Idade Média (MOLLE, 2006 apud CIBIM, 2011). No mesmo contexto, Cibim (2011, p. 28) em sua tese de doutorado nos apresenta um breve relato histórico:

Foi observado no Sri Lanka, no final do primeiro milênio antes de Cristo até o século XIII (MOLLE, 2006, p. 02), o primeiro uso das bacias hidrográficas como unidades administrativas e na China antiga foi verificada a classificação pioneira dos 
recursos hídricos em diversas categorias: tronco, tributários, canais e demais (MOLLE, 2006). Foi, entretanto, na Europa na época do Rei Luis XV que Philippe Buache inaugurou a teoria de sistemas de drenagem para tentar explicar a estrutura de continentes baseados no estudo de montanhas, córregos e rios (GHIOTTI apud MOLLE, 2006).

Ainda conforme citado por Cibim (2011, p. 28):

Surge aí a primeira teoria sobre a bacia hidrográfica como uma área contínua: "um conjunto de diversas nascentes (declives e inclinações) nos quais a água corre e converge para um mesmo rio ou riacho" (tradução livre), tendo sido aperfeiçoada tornando-se a base teórica da divisão do mundo em áreas e regiōes (LACOSTE e HARTHSHORE apud MOLLE, 2006, p. 3).

Neste mesmo contexto histórico, na França em 1964 afasta-se da abordagem tradicional da administração do território, isto é, recortá-lo em circunscrições administrativas (regiões, departamentos e comunas ou municípios), sancionando a Lei n. 64-1.245 (art. 3º) que tomou como base o quadro geográfico natural do ciclo da água para resolver os problemas relacionados à água (SALDANHA MACHADO, 2003).

Conforme Porto e Porto (2008, p. 44), no Brasil, tivemos algumas experiências exitosas antes da implantação definitiva da bacia hidrográfica como unidade de gestão:

No Brasil, o reconhecimento da crescente complexidade dos problemas relacionados ao uso da água levou ao estabelecimento, em 1976, de acordo entre o Ministério das Minas e Energia e o governo do Estado de São Paulo para a melhoria das condições sanitárias das bacias do Alto Tietê e Cubatão. O êxito dessa experiência fez que, em seguida, fosse constituída, em 1978, a figura do Comitê Especial de Estudos Integrados de Bacias Hidrográficas (CEEIBH), e a subsequente criação de comitês executivos em diversas bacias hidrográficas, como no Paraíba do Sul, no São Francisco e no Ribeira de Iguape. Esses comitês tinham apenas atribuições consultivas, nada obrigando a implantação de suas decisōes, e dele participavam apenas órgãos do governo. Mesmo assim, constituíram-se em experiências importantes e foram importantes embriōes para a evolução futura da gestão por bacia hidrográfica.

No final da década de 1980 por iniciativa da sociedade civil, surgem manifestos conclamando o uso da bacia hidrográfica como unidade de gestão territorial, (Porto e Porto, 2008). Estudos sobre os temas Erosão, Manejo e Conservação do Solo e da Água e Planejamento Ambiental são aqueles que mais têm utilizado a bacia hidrográfica como unidade de análise (BOTELHO et al., 2004) pois os cursos de água da bacia são um receptor das atividades que ocorrem na bacia. 
•• Economia Brasileira em Debate

Quadro 1 Municípios da Região metropolitana de Sorocaba e sua relação com o as Bacias Hidrográficas.

\begin{tabular}{|c|c|c|c|}
\hline $\begin{array}{c}\text { Municípios da } \\
\text { região metropolitana } \\
\text { de Sorocaba }\end{array}$ & Sub-bacia & $\begin{array}{l}\text { Municípios da } \\
\text { região metropolitana } \\
\text { de Sorocaba } 2\end{array}$ & Sub-bacia 3 \\
\hline Alambari & Baixo Sorocaba & \multirow{3}{*}{ Mairinque } & Médio Sorocaba \\
\hline \multirow[t]{2}{*}{ Alumínio } & Médio Sorocaba & & Médio Tietê superior \\
\hline & Alto Sorocaba & & Alto Sorocaba \\
\hline Araçariguama & Médio Tietê superior & \multirow{2}{*}{ Piedade } & Baixo Sorocaba \\
\hline \multirow{2}{*}{ Araçoiaba da Serra } & Baixo Sorocaba & & Alto Sorocaba \\
\hline & Médio Sorocaba & Pilar do Sul & Baixo Sorocaba \\
\hline \multirow{3}{*}{ Boituva } & Médio Tietê médio & \multirow{3}{*}{ Porto Feliz } & Médio Tietê médio \\
\hline & Baixo Sorocaba & & Médio Sorocaba \\
\hline & Médio Sorocaba & & Médio Tietê superior \\
\hline \multirow{2}{*}{ Capela do Alto } & Baixo Sorocaba & Salto & Médio Tietê superior \\
\hline & Médio Sorocaba & \multirow{2}{*}{ Salto de Pirapora } & Médio Sorocaba \\
\hline \multirow{2}{*}{ Cerquilho } & Médio Tietê médio & & Baixo Sorocaba \\
\hline & Baixo Sorocaba & \multirow{2}{*}{ São Roque } & Médio Tietê superior \\
\hline Cesário Lange & Baixo Sorocaba & & Alto Sorocaba \\
\hline Ibiúna & Alto Sorocaba & Sarapuí & Baixo Sorocaba \\
\hline \multirow{2}{*}{ Iperó } & Baixo Sorocaba & \multirow{2}{*}{ Sorocaba } & Médio Tietê médio \\
\hline & Médio Sorocaba & & Médio Sorocaba \\
\hline \multirow[b]{2}{*}{ Itu } & Médio Sorocaba & Tatuí & Baixo Sorocaba \\
\hline & Médio Tietê superior & Tietê & Médio Tietê inferior \\
\hline \multirow{4}{*}{ Jumirim } & Médio Tietê médio & Votorantim & Médio Sorocaba \\
\hline & \multirow{3}{*}{ Baixo Sorocaba } & Itapetininga & Baixo Sorocaba \\
\hline & & São Miguel Arcanjo & Alto Paranapanema \\
\hline & & Tapiraí & $\begin{array}{l}\text { Ribeira de Iguape e } \\
\text { Litoral Sul }\end{array}$ \\
\hline
\end{tabular}

Fonte: Elaboração dos autores. Com Base no Relatório Técnico n. 104.269-205. Plano de Bacia da Unidade de Gerenciamento de Recursos Hídricos do Sorocaba e Médio Tietê (UGRHI 10) - Revisão para o atendimento da Deliberação CRH-62. IPT: São Paulo, 2015. Disponível em: http:// www.sigrh.sp.gov.br/public/uploads/documents/7099/smt_rpb.pdf. 
Assim, a bacia hidrográfica se torna ideal para estudos que analisam a interação entre as várias atividades que se dão no seu âmbito: agrícolas, industriais, comerciais, domésticas, pastoris, com reflexos na fauna, na flora, nos agrupamentos humanos e com consequências para a vida social, econômica, política e financeira (PORTO e PORTO, 2008), e a arena ideal para se obter a eficácia do sistema de gestão de recursos hídricos.

O conceito de Região Metropolitana vem corroborar o espírito do coletivo que estava perdendo espaço para o individualismo das cidades como discutido por Seabra (2016). Mas o seu planejamento além necessitar do imperativo de ser tecnicamente bem construído, terá os desafios da pactuação.

A observação dos quadros pode nos dar a dimensão da problemática que se apresenta. Como podemos observar são os municípios que tem sua sede vinculada à Bacia do Sorocaba/Médio Tietê, independentemente em que sub-bacia se encontra ${ }^{5}$.

Já na Região Metropolitana de Sorocaba, temos o município de Itapetininga que têm território na sub-bacia do Sorocaba e Médio Tietê, mas tem sua sede fora desta Bacia. E em verde claro, São Miguel Arcanjo e Tapiraí, que pertencem à Região Metropolitana de Sorocaba, mas não tem território na UGRHI10.

Mesmo que o problema parasse por aí, já, por si só, demandaria estabelecer os pactos de ação e um permanente diálogo com todos os stakeholder e além de necessitar construir políticas públicas sólidas e pactuadas na gestão dos recursos hídricos.

5 A classificação dos municípios nas suas sub-bacias respectivas pode ser encontrada no documento Relatório Técnico n. 104.269-205. "Plano de Bacia da Unidade de Gerenciamento de Recursos Hídricos do Sorocaba e Médio Tietê (UGRHI 10) - Revisão para o atendimento da Deliberação CRH-62. IPT: São Paulo, 2015. Disponível em: http://www.sigrh.sp.gov.br/public/uploads/documents/7099/smt_rpb.pdf 
•• Economia Brasileira em Debate

Quadro 2 Municípios localizados nas sub-bacias da UGRHI10, mas que não pertencem a Região metropolitana de Sorocaba.

\begin{tabular}{|l|l|}
\hline \multicolumn{1}{|c|}{ Municípios } & \multicolumn{1}{c|}{ Sub-bacia } \\
\hline Bofete & Médio Tietê Inferior \\
\hline Botucatu & Médio Tietê Inferior \\
\hline Cabreúva & Médio Tietê Superior \\
\hline Anhembi & Médio Tietê Inferior \\
\hline Conchas & Médio Tietê Inferior \\
\hline Laranjal Paulista & $\begin{array}{l}\text { Médio Tietê Médio } \\
\text { Baixo Sorocaba }\end{array}$ \\
\hline Pereiras & $\begin{array}{l}\text { Médio Tietê Inferior } \\
\text { Baixo Sorocaba }\end{array}$ \\
\hline Porangaba & Médio Tietê Inferior \\
\hline Quadra & Baixo Sorocaba \\
\hline Vargem Grande Paulista & Alto Sorocaba \\
\hline São Manuel & Médio Tietê Inferior \\
\hline
\end{tabular}

Fonte: Elaboração dos autores. Com Base no Relatório Técnico n. 104.269-205. Plano de Bacia da Unidade de Gerenciamento de Recursos Hídricos do Sorocaba e Médio Tietê (UGRHI 10) - Revisão para o atendimento da Deliberação CRH-62. IPT: São Paulo, 2015. Disponível em: http:// www.sigrh.sp.gov.br/public/uploads/documents/7099/smt_rpb.pdf.

A complexidade, portanto, aumenta a dificuldade em resolver as demandas e fazer alinhamentos de pactos políticos jurídicos de municípios que pertencem a Região Metropolitana e não pertencem a mesma Bacia. Os municípios que pertencem a mesma UGRHI, mas não estão submetidos, necessariamente, aos da Região Metropolitana e são partes interessadas em saber, em discutir o que pretende a Região Metropolitana, na regulação das ações antrópicas, uma vez que as ações de planejamento, podem as afetar, mesmo elas estando, naturalmente alheia a esse processo decisório. Assim se apresenta legitimo, que esses outros municípios que não pertencem à Região Metropolitana de Sorocaba, mas que pertençam a UGRHI10, possam se valer do $\mathrm{CBH}$, para ser um participante legitimo de discussões e negociação, no diálogo com a Região Metropolitana de Sorocaba e o seu planejamento.

Embora territorialmente estejam na UGRHI10, os mesmos encontram-se em sedes outras UGRHIs, principalmente por conta dos seus ativos hídricos mais im- 
portantes estarem presentes em outras sub-bacias, ou, em alguns casos, onde a importância hídrica é equivalente em ambas as bacias, as decisões de estar sediado noutra Bacia, se dá por pacto político, identidade histórico-cultural etc. Em alguns casos, há até a demanda de que determinado município, tenha voz e voto em ambos Comitês (Quadro 3).

Quadro 3 Municípios que tem território na UGRHI10 mas que nem pertencem à Região Metropolitanas de Sorocaba e nem tem Sede na Bacia do Sorocaba e Médio Tietê.

\begin{tabular}{|l|l|}
\hline \multicolumn{1}{|c|}{ Municípios } & \multicolumn{1}{|c|}{ Sub-Bacia } \\
\hline Cotia & Alto Sorocaba \\
\hline Dois Córregos & Médio Tietê Inferior \\
\hline Cajamar & Médio Tietê Superior \\
\hline Barra Bonita & Médio Tietê Inferior \\
\hline Elias Fausto & Médio Tietê Superior \\
\hline Guareí & Baixo Sorocaba \\
\hline Igaraçu do Tietê & Médio Tietê Inferior \\
\hline Indaiatuba & Médio Tietê Superior \\
\hline Itapevi & Médio Tietê Superior \\
\hline Jundiaí & Médio Tietê Superior \\
\hline Mineiros do Tietê & Médio Tietê Inferior \\
\hline Piracicaba & Médio Tietê Inferior \\
\hline Pirapora do Bom Jesus & Médio Tietê Superior \\
\hline Rafard & Médio Tietê Médio \\
\hline Rio das Pedras & Médio Tietê Médio \\
\hline Saltinho & Médio Tietê Inferior \\
\hline Santana de Parnaíba & Médio Tietê Superior \\
\hline
\end{tabular}

Fonte: Elaboração dos autores. Com Base no Relatório Técnico n. 104.269-205. Plano de Bacia da Unidade de Gerenciamento de Recursos Hídricos do Sorocaba e Médio Tietê (UGRHI 10) - Revisão para o atendimento da Deliberação CRH-62. IPT: São Paulo, 2015. Disponível em: http:// www.sigrh.sp.gov.br/public/uploads/documents/7099/smt_rpb.pdf

Além disso, muitos por estarem fora da sede, e seus ativos hídricos e suas atividades antrópicas influenciarem diretamente, rios da Bacia do Sorocaba e Médio 
Tietê, não necessariamente podem estar alinhados politicamente com os mesmos projetos e não sofrerá a mesma pressão política que, poderia ter, dos demais participantes, se estivesse sediado no mesmo $\mathrm{CBH}$.

Enquanto cidade-membro de uma Região Metropolitana será necessário a discussão do coletivo, do melhor para todos. A Região Metropolitana de Sorocaba RMS enfrentará o desafio de conversar com seus vizinhos sobre o melhor manejo para (por exemplo) a Área de Proteção Ambiental - APA de Itupararanga.

O rio Sorocaba tem sua formação nos municípios de Ibiúna, Vargem Grande, São Roque e Cotia, com os rios Sorocamirim, Sorocabaçu e Una. A formação do reservatório de Itupararanga envolve ainda os municípios de Mairinque, Alumínio, Votorantim e Piedade. Sendo que seu principal de tributário, rio Sorocamirim nasce no Distrito de Caucaia de Alto, município de Cotia e, que não é membro da RMS. O município de Vargem Grande Paulista, por onde corre esse principal tributário e que possui $100 \%$ de área inserida na APA de Itupararanga (Plano de Manejo da APA, 2010) também não é membro da Região Metropolitana de Sorocaba. O município de Sorocaba, sede da região metropolitana, depende $90 \%$ das águas de Itupararanga (COMITÊ, 2008), portanto, terá que abrir o diálogo, não só com os municípios à montante do rio Sorocaba e que integram a RMS, como com municípios que não são membros da mesma. Assim construir um pacto e interlocução com os $\mathrm{CBH}$ s será uma necessidade.

Para construir políticas públicas coletivas, em realidades distintas e sob a égide de instrumentos diversos, soma-se mais um desafio, as diferenças de administração pública e coalizões políticas determinadas pelos tamanhos das cidades.

Considerando a divisão que Ribeiro (2004 adota, de cidades até 200.000 habitantes e acima disso, para fazer a sua análise, temos uma manifestação clara disso na Região Metropolitana. Sorocaba com população de 652.481, está, portanto, bem acima de 200.00 habitantes e, nenhuma das outras 26 cidades atingem 200.000 habitantes. Itu, com 168.643, Itapetininga, com 158.561, Tatuí com 117.823, e Salto com 115.193, são as que mais se aproximam de $200.000 .^{6}$

Há que considerar que esse texto de Ribeiro foi publicado, em 2004 onde as redes sociais ainda eram incipientes e o judiciário mais tímido. Algumas coisas

6 Ribeiro, (2004) aponta, no seu artigo aponta que, conforme muda o tamanho das cidades (divisão de cidades com até 200 mil habitantes e acima dessa população), os determinantes das pactuações políticas, a importância das lideranças representativas, o papel da imprensa, o papel da ação comunitária em ambos os casos, bastante distintos. 
qualitativamente vêm mudando, mas muito delas continuam presentes nas cidades pequenas. Esse é mais um problema adicional que qualquer planejamento, seja hídrico ou de gestão urbana terá de considerar, a diferente dinâmica e pactuação que ocorre entre cidades metropolitanas e pequenas.

\section{RECURSOS HÍDRICOS. UMA AGENDA INEXORÁVEL}

A disponibilidade de água e seu acesso para a população e para as atividades econômicas é um dos principais elementos a se considerar na gestão de áreas urbanas. A existência humana e todas as atividades econômicas são dependentes em menor ou maior grau do uso e da qualidade da água. Apesar desta importância fundamental, foi somente em 2010 que a ONU reconheceu a água e o saneamento como direitos humanos básicos.

Água para abastecimento humano e para uso diário nos processos de higiene e alimentação deve ser prioritária no planejamento. Cada pessoa necessita de 50 a 100 litros de água por dia para manter somente suas atividades básicas e garantir a saúde. Esta demanda, em função da importância deve ser primordial.

$\mathrm{Na}$ gestão dos recursos hídricos alguns conceitos são básicos: a) a bacia hidrográfica como unidade de gestão; b) a garantia dos usos múltiplos sempre que possível; c) a conservação dos recursos hídricos de montante (nascente) para jusante (rios maiores).

Não há como gerenciar o recurso sem considerar a disponibilidade e a demanda na bacia hidrográfica. Mesmo sendo possível transportar água entre bacias, o processo é sempre muito caro e de difícil gerenciamento além de contribuir para o conflito entre regiōes pelo uso do recurso. Este conflito pode ser observado em várias regiōes onde a demanda se sobrepóe a oferta, como a Região Metropolitana de São Paulo com as bacias do Rio Piracicaba (Sistema Cantareira) e a Bacia do Rio Paraíba do Sul.

Apesar da dessedentação humana ser o uso prioritário e que necessita de melhor qualidade para permitir o tratamento e a distribuição com condições de potabilidade, outros usos são também significativos para a manutenção das sociedades como a geração de energia através de hidroelétricas, a irrigação, a pesca e a diluição de efluentes. Todos estes usos podem conflitar tanto na quantidade como na qualidade com a água para abastecimento.

A diluição de efluentes talvez seja o uso que mais afeta a qualidade da água e, portanto, que precisa de mais ações para reduzir seu impacto em áreas urbanas. Mesmo os sistemas de tratamento de esgoto mais avançados não garantem uma 
qualidade final do efluente nas mesmas condições de águas naturais não impactadas e a qualidade do recurso tende a se degradar lentamente.

A redução da qualidade da água também é um subproduto da irrigação, que contribui com o escoamento superficial das áreas agrícolas e a entrada de fertilizantes e agrotóxicos nos ecossistemas aquáticos. Além disso, muitas áreas rurais não têm saneamento básico contribuindo com esgoto doméstico e subprodutos da produção, como lavagem de hortaliças e frutas, para a disposição de efluentes nos corpos de água.

A rede hidrográfica funciona como um acumulador dos impactos da bacia. Qualquer processo de manejo, voltado a manutenção da quantidade e qualidade de água precisa considerar açôes a partir das nascentes e pequenos rios, mais vulneráveis a montante, até o rio principal, mais estável a jusante.

Muitos conflitos no gerenciamento dos recursos hídricos estão relacionados no uso da água entre municípios de montante com os de jusante. Por exemplo, na bacia do Sorocaba, os municípios da cabeceira do Rio na Bacia do Alto Sorocaba, tem como uso principal para o Rio Sorocaba a disposição de efluentes não tratados e irrigação, usando para abastecimento rios de outras bacias ou efluentes do rio Sorocaba menos impactados. Este uso acaba causando um conflito com os municípios mais a montante, como Sorocaba e Votorantim, que utilizam o Rio Sorocaba para abastecimento público.

Além disso, o desenvolvimento das áreas urbanas muitas vezes valoriza as regiōes mais altas, onde se encontram as nascentes, o que leva a impactos nos principais formadores do rio principal. Esta forma de ocupação urbana com impermeabilização de regiōes altas aliado ao uso das baixadas nas margens dos rios para vias de acesso é um dos principais causadores tanto da redução da quantidade da água na seca e o excesso no verão (enchentes) como a perda da qualidade de água.

A Região Metropolitana de Sorocaba na gestão dos Recursos Hídricos tem alguns grandes desafios: a) organizar a ocupação urbana dos municípios de uma mesma bacia para que os usos de um município não prejudique o uso da água nos municípios a jusante; b) incentivar e pressionar para que o saneamento e abastecimento de água sejam prioritários em todos os municípios; c) criar regras para a gestão conjunta de recursos hídricos juntos com os mecanismos já existentes como os CBHs e os Consórcios Municipais; d) organizar os usos múltiplos da água nos municípios para garantir o abastecimento público além de permitir os outros usos como irrigação e geração de energia. 


\section{4. ÁGUA BEM GERIDA. GARANTIR A BIODIVERSIDADE É GARANTIR A AGRICULTURA E A ECONOMIA METROPOLITANA}

Componente essencial dos ecossistemas e dos ciclos naturais, o solo também é um suporte fundamental para os sistemas agrícolas. Os microrganismos são os principais responsáveis pelo processo de mineralização dos nutrientes, mas é a fauna de solo que exerce um papel de regulação nas populações microbianas. (CORREIA; OLIVEIRA, 2006).

A predação seletiva de fungos e bactérias, feita especialmente pela microfauna; a estimulação, digestão e disseminação de microrganismos ingeridos pela macrofauna e a fragmentação dos detritos realizada pelas meso e macrofauna interferem na decomposição da matéria orgânica e alteram a disponibilidade de nutrientes para as plantas (CRAGG; BARDGETT, 2001).

A vegetação determina grande parte do estabelecimento da fauna de solo, a qualidade e quantidade do material decíduo, especialmente em ambientes tropicais, podem afetar as populações da macrofauna de solo, resultando em uma mobilização diferencial de nutrientes com consequências para a ciclagem de nutrientes e a fertilidade do solo (WARREN; ZOU, 2002).

No município de Sorocaba foram realizados estudos utilizando imagens de satélites com intervalo de 5 anos: 1990, 1995, 2000, 2005 e 2010 demonstrando que Sorocaba vem apresentando importantes variaçôes no uso do solo e da cobertura vegetal. Foram observados que de 1990 a 2000 ocorreu um aumento gradativo das áreas verdes, enquanto que a partir de 2000 essa tendência foi invertida, demonstrando expressiva perda de cobertura vegetal até 2010 (LOURENÇO et al., 2014).

As áreas de uso agrícola tiveram um expressivo aumento em 1995, em 2000 houve uma queda drástica que ocorreu devido ao período de entressafras e até 2010 essas áreas aumentaram gradativamente novamente. (LOURENÇO et al., 2014).

As áreas de solo degradado permaneceram praticamente constantes, enquanto que as áreas urbanas se expandiram devido ao crescimento da cidade, a implantação da Rodovia Dr. Celso Charuri e a ampliação da Rodovia Raposo Tavares também causaram um aumento significativo da malha viária do município, consequentemente essas áreas foram uma das principais responsáveis pela retirada de cobertura vegetal, essas mudanças acarretaram a perda da biodiversidade, fragmentação dos remanescentes florestais do município e aumento do $\mathrm{CO}_{2}$, causado pelas indústrias, crescimento populacional e aumento da frota de veículos. (LOURENÇO et al., 2014). 
Ainda segundo Lourenço et al., 2014, a paisagem atual da região de Sorocaba é composta de um mosaico de grandes áreas de monoculturas e um grande centro urbano e industrial, com algumas pequenas manchas de vegetação natural e estas vêm sofrendo diversos impactos negativos nas áreas urbanas e rurais havendo grande comprometimento de sua diversidade e estabilidade.

Agricultores líderes, cientistas e grupos governamentais estão reunidos em torno do princípio da "intensificação sustentável", um modelo que consiste na busca do aumento da produção de alimentos nas áreas já existentes, usando métodos que apresentam menor pressão sobre o ambiente segundo Mikkelsen (2015).

Ainda, segundo o mesmo autor para atender aos princípios da intensificação sustentável deve-se implementar práticas e manejo de solos abrangentes, o que inclui a manutenção do solo coberto em boa parte do ano, utilizando plantio direto e rotação de culturas apropriadas; implementação de técnicas integradas de manejo de nutrientes, eliminando as restrições do solo que limitam o crescimento da planta, e adoção de práticas de prevenção da erosão e conservação da água.

Ao garantir a biodiversidade do solo e sua riqueza, garantimos produtividade e renda para agricultores e famílias, ao mesmo tempo que garantimos que a degradação seja mitigada.

\section{CONSIDERAÇÕES FINAIS}

Com recortes tão diferentes, um dado pela origem dos recursos hídricos e suas nascentes e a outra pela divisão e agrupamento político do território o problema se impõe: como alinhar politicamente e no planejamento os municípios da Região Metropolitana de Sorocaba e as políticas, práticas e demandas dos CBHs, uma vez que existem municípios que não se encontram na Região Metropolitana de Sorocaba e pertencem à nossa Bacia e municípios que pertencem à Região Metropolitana de Sorocaba e não pertencem à nossa Bacia. Soma-se a isso que sofremos a influência de municípios que nem pertencem à Região Metropolitana de Sorocaba e nem à nossa Bacia, mas, cuja ação antrópica, afeta nossos recursos hídricos, e, portanto, a qualidade do nosso estoque hídrico e de gestão.

Soma-se à essa complexidade que, a práxis política e de pactuação é diferente numa cidade metropolitana e numa cidade com menos de 200 mil habitantes.

As agendas políticas e legais, em muitos casos tendem a atropelar um processo mais profundo de discussão e pactuação. Por outro lado, os custos de negociação não podem perdurar ad aeternum. 
Buscar o equilíbrio entre uma pactuação-coalizão consistente entre aspectos hídricos e de gestão territorial que se apresentarão à Região Metropolitana de Sorocaba e ao $\mathrm{CBH}$ será fundamental importância para que possamos não só garantir a qualidade de vida da nossa região, como também manter a grande produção agrícola que aqui está.

Água, além de essencial para toda a vida do planeta, também garante a biodiversidade que, atua sobre a qualidade do solo, e, portanto, sendo um dos determinantes da produtividade da agricultura.

O zelo pela gestão e manutenção dos recursos hídricos passa por acomodar as diversas matizes políticas e de interesse, sobrepondo o interesse coletivo e público sobre qualquer interesse particular, sob qualquer justificativa. Para isso só o diálogo com as instâncias adequadas à discussão bem como entre as que tem poder de mando e veto, poderá resultar em boas políticas públicas.

\section{REFERÊNCIAS}

BARETTA, Dilmar et al. Análise multivariada da fauna edáfica em diferentes sistemas de preparo e cultivo do solo. Pesquisa Agropecuária Brasileira, Brasília, v. 41, n. 11, p. 1675-1679, nov. 2006. Trimestral. Disponível em: <https://seer.sct. embrapa.br/index. php/pab/article/view/7331/4376>. Acesso em: 05 abr. 2017.

BRASIL. Lei 9433 de 8 de janeiro de 1997. Institui a Política Nacional de Recursos Hídricos, cria o Sistema Nacional de Gerenciamento de Recursos Hídricos, regulamenta o inciso XIX do art. 21 da Constituição Federal, e altera o art. $1^{\circ}$ da Lei n. 8.001, de 13 de março de 1990, que modificou a Lei n. 7.990, de 28 de dezembro de 1989. Disponível em: http://www.planalto.gov.br/ccivil_03/leis/L9433.htm\#art33iii. Acesso em: 22 abr. 2017

CIBIM, J. C. O desafio da Governança nas bacias hidrográfica transfronteiriças internacionais: um olhar sobre a bacia do rio Prata. 2012. 189 f. Tese (Doutorado) - Universidade de São Paulo, São Paulo, 2012.

CORREIA, Maria Elizabeth Fernandes; OLIVEIRA, Luís Cláudio Marques de. Importância da Fauna de Solo para a Ciclagem de Nutrientes. Embrapa, Brasília, n. 4, p. 77-100, 01 dez. 2006. Mensal. Disponível em: <http://www.agencia.cnptia.embrapa. br/recursos/biotacap4ID-QOAsuHeSsM.pdf>. Acesso em: 04 abr. 2016.

CRAGG, R. G.; BARDGETT, R. How changes in soil faunal diversity and composition within a trophic group influence decomposition processes. Soil Biology and Biochemistry, Oxford, v. 33, p. 2073-2081, 2001.

EMPLASA - Empresa Paulista de Planejamento Metropolitana S/A. Regiāo Metropolitana de Sorocaba. Disponível em: https://www.emplasa.sp.gov.br/RMS. Acesso em: 20 abr. 2017. 
INSTITUTO DE PESQUISA TECNOLÓGICAS - IPT. Relatório Técnico n. 104.269205. Plano de Bacia da Unidade de Gerenciamento de Recursos Hidricos do Sorocaba e Médio Tietê (UGRHI 10). Revisão para Atendimento da Deliberação CRH 62. São Paulo: IPT, 2008. Disponível em: http://www.sigrh.sp.gov.br/public/uploads/documents/7099/ smt_rpb.pdf. Acesso em: 22 abr. 2017.

LOURENÇO, Roberto Wagner et al. Geoprocessamento como ferramenta de gestão e planejamento ambiental: $\mathrm{O}$ caso da cobertura vegetal em áreas urbanas. In: SMITH, Welber Senteio; MOTA JUNIOR, Vidal Dias da; CARVALHO, Jussara de Lima (Org.). Biodiversidade do Município de Sorocaba. Sorocaba: Secretaria do Meio Ambiente, 2014. Cap. 4. p. 65-78.

MIKKELSEN, Robert. Intensificação sustentável para proteger os recursos do solo. International Plant Nutrition Institute: Informações Agronômicas. Georgia, p. 18-19. jun. 2015. Disponível em: <http://www.ipni.net/publication/ia-brasil.nsf/0/65DB7322D537 2B4E83257E7F004C68FC/\$FILE/Page1-2-150.pdf>. Acesso em: 09 abr. 2017.

PORTO, M. F. A.; PORTO, R. L. L. Gestão de bacias hidrográficas. Revista Estudos Avançados, São Paulo, v. 22, n. 63, p. 43-60, 2008.

RIBEIRO, Francisco C. Das coalizões advocatórias às coalizões defensivas: uma análise da forma de administração condicionada pela dimensão dos municípios. Revista de Estudos Universitários, Sorocaba, v. 30 n. 2 p. 62-76, 2004.

RIBEIRO, F. C. et al. Elementos da Economia Agrícola e Olericultura da Região Metropolitana de Sorocaba. Um celeiro produtivo e farto para Pesquisas. Sorocaba: inédito, 2017. 49p.

SALDANHA MACHADO, C. J. Gestão francesa de recursos hídricos: descrição e análise dos princípios jurídicos. Revista Brasileira de Recursos Hidricos, Porto Alegre, v. 8, n. 4, p. 31-47, out./dez. 2003.

SÃO PAULO. (Estado) Lei Complementar 1.241, de 8 de maio de 2014. Cria a Região Metropolitana de Sorocaba e dá providências correlatas. Disponível em: http://www.al.sp.gov. br/repositorio/legislacao/lei.complementar/2014/lei.complementar-1241-08.05.2014.html. Acesso em: 22 abr. 2017.

SÃO PAULO (Estado) Lei Complementar 1.289, de 29 de junho de 2016. Integra na Região Metropolitana de Sorocaba o Município de Itapetininga. Disponível em: http://www.al. sp.gov.br/repositorio/legislacao/lei.complementar/2016/lei.complementar-1289-29.06.2016. html. Acesso em: 22 abr. 2017.

SEABRA, ODETTE CARVALHO. O urbano: destino histórico da sociedade moderna. In FRANCA, G.C. et al. (Org.). Cidade Natureza Educação Olhares marxistas. São Paulo: EJR Xamã Editora Ltda. 2016, p. 79.

WARREN, M. W.; ZOU, X. Soil macrofauna and litter nutrients in three tropical tree plantations on a disturbed site in Puerto Rico. Forest Ecologyand Management, Amsterdam, v. 170, p. 161-171, 2002. 